\title{
Keselarasan antara Baru dan Lama Eks-Bioskop Indra Surabaya
}

\author{
Shinta Mayangsari dan M. Dwi Hariadi \\ Departemen Arsitektur, Fakultas Teknik Sipil dan Perencanaan, Institut Teknologi Sepuluh Nopember (ITS) \\ e-mail: dwihariadi@yahoo.co.id
}

\begin{abstract}
Abstrak-Surabaya menjadi salah satu kota Metropolitan besar di Indonesia dengan pertumbuhan ekonomi kota yang pesat. Kegiatan perdagangan kota Surabaya yang pesat diharapakan juga sejalan dalam bidang lain terutama dalam hal pelestarian bangunan cagar budaya (BCB). Pemanfaatan bangunan cagar budaya (BCB) menjadi fungsi jasa dan komersial adalah jawaban dari masalah pelestarian BCB dan kaitannya dengan kontribusi dalam perekonomian kota secara aktif. Objek BCB yang dipilih adalah eks-Bioskop Indra Surabaya. Bangunan bergaya khas Nieuwe Zakelijkheid ini berdiri sejak 1910. Kondisi bangunan saat ini tidak berfungsi dan terbengkalai. Pelestarian eks-Bioskop Indra dilakukan dengan cara adaptasi (adaptivereuse), yaitu mengubah eksisting yang terbengkalai untuk difungsikan kembali dengan fungsi baru (berupa kantor sewa $\&$ resto) tanpa menuntut perubahan drastis dan tetap mempertahankan ciri khas. Konsep form follows form sebagai dasar untuk merancang massa baru agar selaras dengan bangunan lama. Pendekatan kontekstualisme dan metode insertion-transition dipilih untuk mencapai keterpaduan antara yang lama dan baru.
\end{abstract}

Kata Kunci-adaptive-reuse, bangunan cagar budaya, insertion, kontekstualisme, transition.

\section{PENDAHULUAN}

$\mathrm{S}_{\mathrm{d}}^{\mathrm{u}}$ URABAYA merupakan ibukota Propinsi Jawa Timur dengan luas wilayah kurang lebih $374 \mathrm{~km} 2$. Kota Pahlawan ini juga kota metropolitan terbesar kedua di Indonesia setelah Jakarta. Tingkat perekonomian dan investasi di Surabaya tumbuh dan bekembang pesat. Pesatnya perekonomian kota diharapkan sejalan dengan bidang lain terutama pelestarian bangunan cagar budaya. Banyak objek cagar budaya baik kawasan maupun bangunan sudah dilestarikan, namun ada juga beberapa masih belum lestari.

Salah satu bangunan yang berada di kawasan cagar budaya namun belum lestari adalah bangunan Eks-Bioskop Indra. Bangunan yang berada di persimpangan antara Jl. Gubernur Suryo dan Jl. Panglima Sudirman ini sudah berdiri sejak tahun 1910. Bangunan yang terkenal akan fungsinya sebagai bioskop kenamaan Surabaya ini memiliki langgam aristektur yang khas, yaitu selasar pada area pedestrian. Hal ini membuat bangunan lebih menonjol dari sekitarnya. Hal yang miris dari kondisi bangunan yang tidak dimanfaatkan, membuatnya kotor dan tidak terawat. Penggunaan kembali atau adaptive reuse [1] dari bangunan terbengkalai ini dengan menawarkan fungsi ekonomi (rental office dan restoran) [2] akan membuat bangunan secara aktif berkontribusi dalam pelestarian $\mathrm{BCB}$ dan ekonomi kota sekaligus.

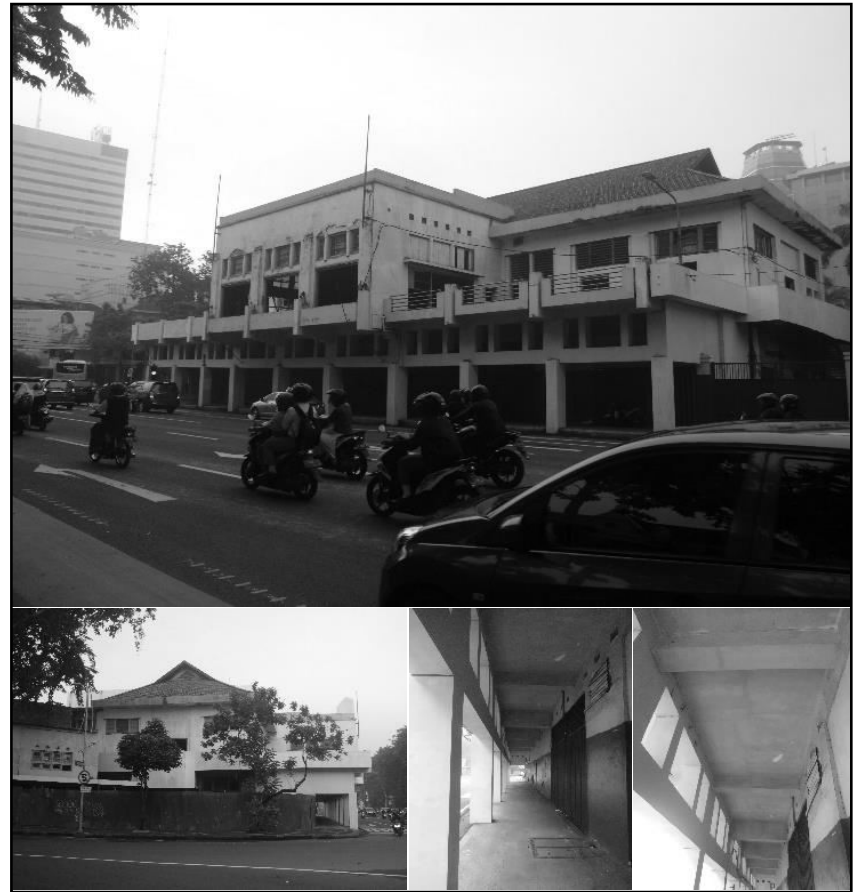

Gambar 1. Kondisi Eks-Bioskop Indra saat ini.

(Sumber: Dokumentasi penulis)

\section{EKPLORASI DAN PROSES RANCANG}

Perencanaan dan perancangannya menggunakan pendekatan kontekstualisme. Kontekstualisme menekankan bahwa bangunan harus mempunyai kaitan dengan lingungan atau bangunan yang berada di sekitarnya. Keterkaitan tersebut didapat dari proses menghidupkan kembali sesuatu yang ada dalam eksisting ke bangunan baru [3].

Terletak di persimpangan JL. Gubernur Suryo dan Jl. Jendral Sudirman Surabaya, lokasi dari rental office dan resto ini menempati lahan dari bangunan Eks-Bioskop Indra.

Dalam proyek ini, rental office \& resto adalah tempat aktivitas ekonomi dan sosial kota yang terwadahi pada bangunan cagar budaya yang unik dan khas sebagai latarnya. Fungsi rental office \& resto ini diambil dari pertimbangan peruntukkan lahan eksisting dan kondisi sekarang. Hal ini berarti bahwa fungsi yang diusulkan adalah untuk menunjang aktivitas perekonomian kota Surabaya. Fungsi baru sebagai rental office \& resto tidak mampu ditampung oleh luas bangunan eksisting, maka dari itu dilakukan penambahan massa atau ekstensi. Hasilnya terdapat dua jenis massa yaitu massa lama (eksisting) dan massa baru (ekstensi). Peletakkan ekstensi berada di belakang eksisting sesuai dengan peraturan dan ketersediaan lahan. 
Penggabungan dua massa antara eksisting dan ekstensi dilakukan dengan metode insertion. Insertion atau penyisipan dilakukan dengan menggabungkan massa baru secara permukaan atau tepian ke massa lama. Proses ini tidak mengganggu bentuk asli bangunan lama. Massa baru hanya menyinggung secara permukaan atau tepian dari massa lama [4].

Desain pada massa baru harus memerhatikan dan menyesuaikan prinsip desain eksisting. Hal ini dilakukan agar massa baru bisa padu dan sesuai dengan yang lama, sehingga mampu membingkai dan menonjolkan eksisting dengan apik. Maka dari itu, dalam perancangan ekstensi digunakan prinsip desain dari eksisting. Prinsip desain eksisting yang diadopsi adalah bentukan dasar eksiting seperti geometri kotak, segitiga, dan elemen struktur yang menonjol. Bentukan dasar tersebut diolah kembali dengan cara transformasi adisi (penambahan), transformasi substraksi (pengurangan), perulangan bentuk dan irama [5].

Tampilan yang ingin ditampilkan ke luar adalah lebih luwes dari kesan bangunan fungsi perkantoran. Kesan luwes diterapkan dengan permainan material baik warna maupun tesktur. Warna yang diterapkan juga berdasar dari warna eksisting yaitu warna - warna material seperti warna merah dari atap, putih cat embok, coklat kayu, dan transparan kaca jendela [6].

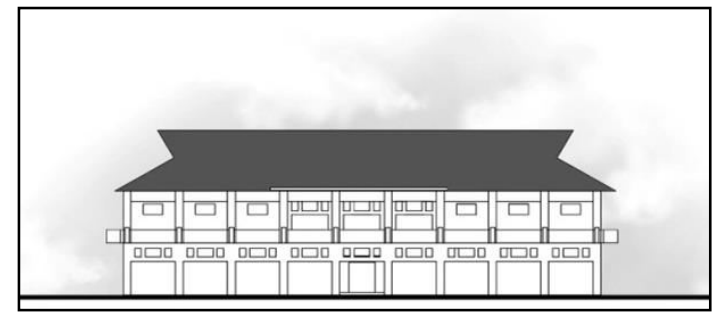

Gambar 2. Fasad Eksisting.

(Sumber: Dokumen penulis)

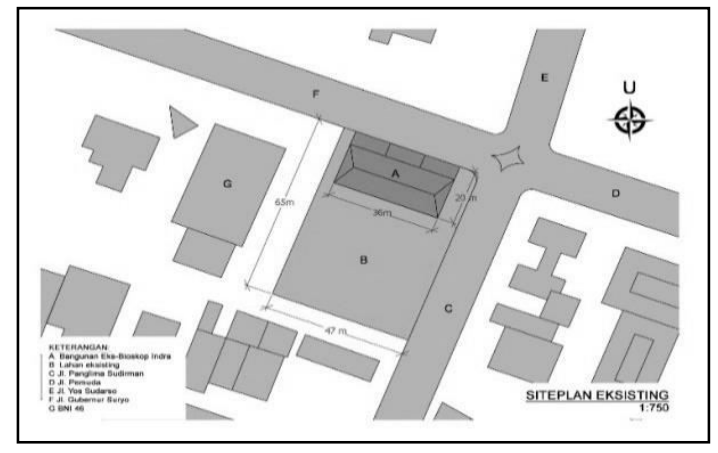

Gambar 3. Lokasi Eks-Bioskop Indra Surabya.

(Sumber: Dokumen penulis)

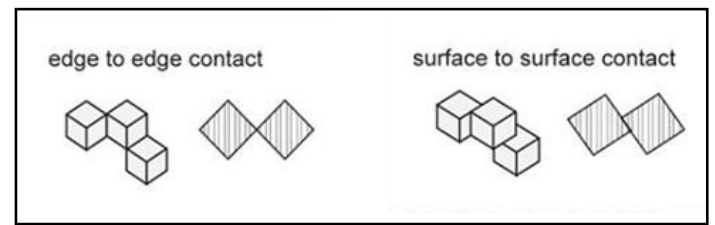

Gambar 4. Metode Penggabungan Massa dengan Insertion. (Sumber: Fisher-Gewirtzman, 2016)

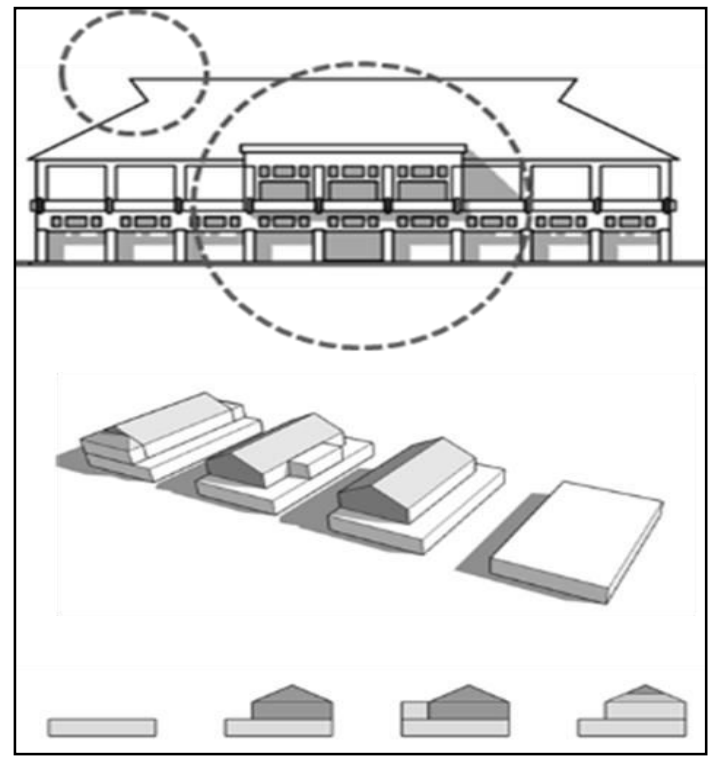

Gambar 5. Elemen Eksisting yang diaopsi ke Ekstensi. (Sumber: Dokumen penulis)

\section{HASIL RANCANG}

\section{A. Extention Building: Form Follows Form (Transition)}

Konsep form follows form yaitu desain ekstensi mengikuti prinsip desain eksisting. Prinsip desain yang diterapkan adalah penggunaan bentuk geometri kotak sebagai bentuk dasar ekstensi.

Mula - mula ekstensi diposisikan pada area belakang eksisting. Hal ini dilakukan sesuai dengan peraturan dan ketersediaan area lahan yang kosong.

Pengolahan bentukan dasar geometri dengan pengurangan volume dan ukuran, hingga didapat bentuk sepertu huruf ' $U$ ' terbalik. Hal ini dilakukan untuk mendapatkan akses sirkulasi udara yang baik, mengingat bentukan eksisting lebih besar ( 5 lantai).

Lalu perulangan bentukan ' $U$ ' pada lantai 3 hingga 5 dengan menurangi volume untuk bagian sayap kanan. Pengurangan volume tersebut mengakibatkan bentukan menjadi berundak. Bentukan berundak tersebut kemudian dihaluskan dengan menghubungkan lantai 5 ke 3, sehingga permukaan berundak menjadi bidang miring. Penerapan bidang miring pada bagian atap lantai 5 adalah sebagai elemen estetika dan penanda fasad utama bangunan ekstensi.

\section{B. Extention Building Facade: Adopsi Struktur yang Menonjol pada Eksisting}

Elemen struktur yang menonjol pada eksisting, yaitu kolom dan balok, diadopsi menjadi fasad massa baru dengan mengambil kolom, yang dianggap sebagai bentukan vertikal. Bentukan vertikal tersebut dibuat sebagai selubung dan bukaan ekstensi. Perbedaan material pada bentukan vertikal, masif dan transparan mengakibatkan tersiptanya selubung dan bukaan. Pewarnaan fasad dengan warna mirip eksisting, merah, putih, dan hitam sebagai peredam kontras merah dan putih. 


\section{New Interior}

Pada bagian dalam (interior) dari bangunan lama yang kotor dan rapuh, dilakukan peremajaan dengan mengganti elemen yang rusak. Hal tersebut diterapkan dengan penambahan dinding untuk fungsi ruang resto, penggantian konstruksi atap dari kayu menjadi baja ringan, dan perletakan ornamen hias pada kolom dan balok.

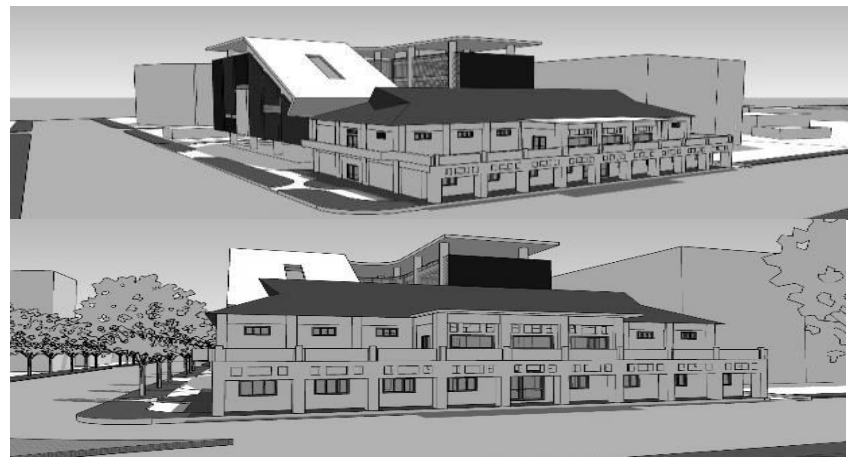

Gambar 6. Rental Office \& Resto.

(Sumber: Dokumen penulis)

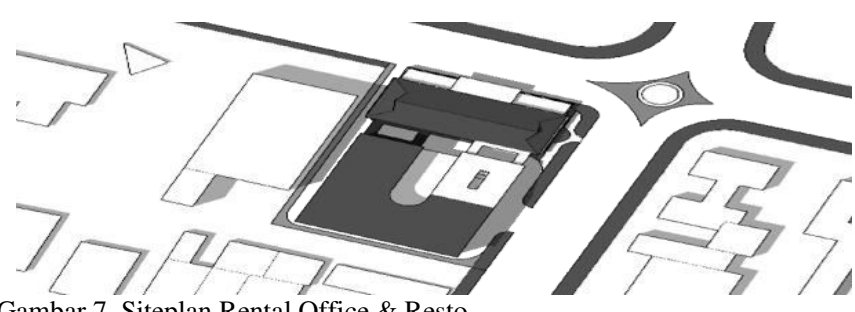

Gambar 7. Siteplan Rental Office \& Resto.

(Sumber: Dokumen penulis)

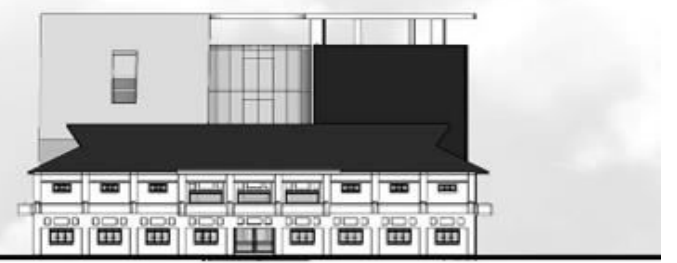

Gambar 8. Tampak Timur Laut Rental Office \& Resto. (Sumber: Dokumen penulis)

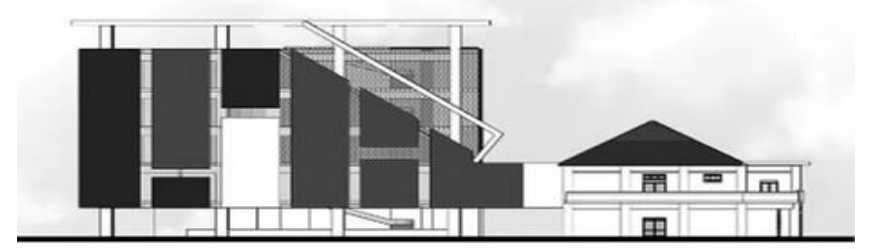

Gambar 9. Tampak Tenggara Rental Office \& Resto (Sumber: Dokumen penulis)
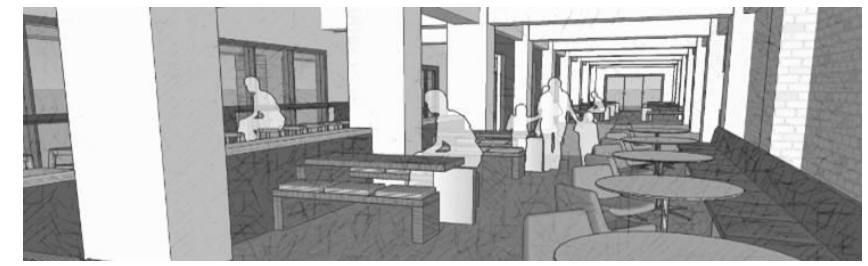

Gambar 10. Interior Baru pada Eksisting Fungsi Resto.

(Sumber: Dokumen penulis)

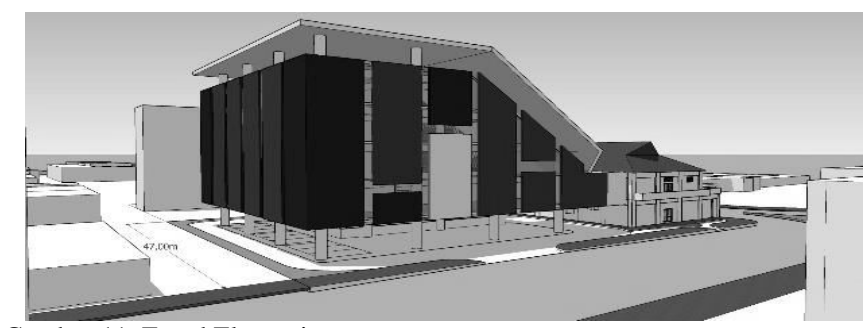

Gambar 11. Fasad Ekstensi.

(Sumber: Dokumen penulis)

\section{KESIMPULAN/RINGKASAN}

Penerapan fungsi rental office \& resto ke dalam bangunan cagar budaya terbengkalai mampu menjawab permasalahan pelestarian bangunan cagar budaya sekaligus. Bangunan cagar budaya yang terfungsikan secara otomatis akan terjaga dan terawat kondisi nya. Keuntungan tambahan adalah fungsi yang diusulkan yaitu rental office \& resto yang membuat bangunan secara aktif berkontribusi ke dalam beberapa bidang sekaligus, ruang untuk aktivitas ekonomi, publik, dan terjaminnya pelestarian objek.

Desain yang berkonsep pada form follows form memastikan massa baru selaras dan sesuai dengan massa lama. Bukan untuk mendominasi, tapi membingkai dan menjadi satu kesatuan dengan lingkungan.

\section{DAFTAR PUSTAKA}

[1] Pemerintah Kota Surabaya, "Peraturan Daerah Kota Surabaya Nomor 5 Tahun 2005 tentang Pelestarian Bangunan dan/atau Lingkungan Cagar Budaya," Surabaya, 2005.

[2] Pemerintah Kota Surabaya, "[2] Peraturan Wali Kota Nomor 57 Tahun 2015 tentang Pedoman Teknis Pengendalian Pemanfaatan Ruang dalam Rangka Pendirian Bangunan di Kota Surabaya," Surabaya, 2015.

[3] K. Jormakka, Basic Design Methods. Boston: Birkhäuser, 2003.

[4] S. S. Brooker, Rereadings SS Interior Architecture and The Design Principles of Remodelling Exixting Buildings. London: RIBA Enterprise Ltd, 2004.

[5] F. D. K. Ching, Arsitektur: Bentuk, Ruang, dan Tatanan Edisi Ketiga. Jakarta: Erlangga, 2007.

[6] B. Irawan and T. Priscilla, Dasar - Dasar Desain. Jakarta: Griya Kreasi, 2013. 